DOI: $10.14451 / 1.171 .58$

\title{
БИЗНЕС-МОДЕЛЬ НАЦИОНАЛЬНЫХ НЕФТЯНЫХ КОМПАНИЙ (ННК)
}

\author{
(C) 2019 Иову Теодор Тудорович \\ аспирант \\ Российская академия народного хозяйство и государственной службы при Президенте РФ \\ 119571, г. Москва, проспект Вернадского, 82 \\ E-mail: iovu.teodor@mail.ru
}

В этом исследование дается оценка и обзор бизнес-моделей, проблем и возможностей национальных нефтяных компаний, их стратегий и возникающих тенденций. Роль национальной нефтяной компании (НHK) продолжает развиваться по мере того, как глобальный энергетический ландшафт меняется, отражая изменения в спросе, открытие новых сверхглубоких нефтяных месторождений, а также национальные и геополитические разработки. НHК, которые традиционно считаются хранителями природных ресурсов своей страны, как правило, владеют и управляют всей национальной цепочкой поставок нефти и газа от добычи до переработки. В последние годы ННК стали не только партнерами по совместным предприятиям по всему миру с крупными нефтяными компаниями, но и все чаще выступают в качестве конкурентов Международным нефтяным компаниям (МНК). Многие ННК в настоящее время более активно участвуют в слияниях и поглощениях (M \& A), тем самым увеличивая количество НHК, стремящихся к международным операциям по приобретению и активам в апстрим и даунстим направлении.

Ключевые слова: Национальные нефтяные компании, Международные нефтяные компании, технологии, бизнес модель.

\section{Введение}

Национальные нефтяные компании (ННК) определяются как те нефтяные компании, чей значительный пакет акции принадлежат государству, и чья миссия состоит в том, чтобы работать в интересах своей страны. Традиционная миссия ННК заключается в том, чтобы предоставить стратегическим инвесторам, как совладельцам и поставщикам услуг, доступ к углеводородным ресурсам своей страны. ННК владеют и управляют цепочкой поставок нефти и газа в своей стране. Основными движущими факторами инвестиций между ННК и международными нефтяными компаниями (МНК) являются обеспечение доступа к углеводородным ресурсам, передача знаний о новейших технологиях, инженерный опыт, а также навыки управления проектами. Как это видно на примере Венесуэлы и России, ННК могут использоваться для продвижения как социальных, так и политических программ, а также экономических. Неспособность китайского ННК приобрести американскую компанию (UNOCAL) с международными активами дает сигнал о том, что ННК должны проводить более тщательную политическую экспертизу при проведении трансграничных слияний и поглощений (M \& A). Слияния и поглощения всегда были фактором, стимулирующим рост в нефте- газовом секторе. Рынок слияний дает 423 миллиарда долларов в 2016 году и 408 миллиардов долларов в 2017 году в энергетическом секторе из общего объема слияний и поглощений в мире, равного 2277 миллиардов долларов и 2237 миллиардов долларов. ННК бывают разных форм, но большинство из них имеют как апстрим (разведка и добыча), так и даунстрим (переработка и сбыт). Исторически ННК работали в основном в своих странах, хотя развивающаяся тенденция заключается в том, что они выходят на международный уровень. Примеры ННК включают Saudi Aramco (крупнейшая интегрированная нефтегазовая компания в мире), Kuwait Petroleum Corporation (KPC), Petrobras, Petronas, PetroChina, Sinopec, StatOil и малазийский НHК. Азиатские государственные компании НHК, особенно из Китая и Индии, находятся на переднем крае стратегических трансграничных инвестиций, поскольку их правительства стремятся подготовиться к долгосрочным проблемам с поставками энергии. В то же время увеличение нефтяного богатства, вызванное ростом цен на нефть, побудило правительства таких разных стран, как Россия, Венесуэла, Боливия и Эквадор, предоставить больше политических и экономических рычагов своим национальным энергетическим лидерам. Это достигается на их местном рынке 
путем пересмотра законов, контрактов, налогов и роялти. ННК начали выходить на международный рынок, занимаясь стратегической инвестиционной деятельностью и приобретая полный или частичный контроль над иностранными компаниями в секторах, представляющих стратегический интерес для национального развития. В регионе Совета сотрудничества стран Залива (ССЗ) существует ряд ННК, которые имеют возможность расширяться за пределы обслуживания своих внутренних рынков. Этому процессу частично препятствует неадекватность корпоративных структур и отсутствие информации в регионе GCC. Во всем мире этому препятствует рост экономического национализма и дебаты об экономическом суверенитете, безопасности, владении активами и восприятии на западе, что ННК не должны стремиться к приобретению МНК. Несомненно, политические соображения влияют на международную инвестиционную политику ННК. Возникающая тенденция, обусловленная ростом ННК, изменила в пользу последних баланс контроля над большинством мировых углеводородных ресурсов. Для ННК расширился прямого доступ к капиталу, рабочей силе и технологиям, что способствовало возникновению собственных компетенции. ННК расширяют свои возможности по проведению аутсорсинга для многих операций через нефтесервисные компании (ОФСК), тем самым расширяя диапазон своей компетенции. Кроме того, смена бизнес-моделей ННК ставит задачи перед МOK и независимыми лицами, ставя под сомнение устойчивость их бизнес-модель владения ресурсами. Среди этих проблем - снижение добычи на существующих нефтяных месторождениях, сложность замены запасов нефти и газа в зонах с ограниченным доступом, быстрое истощение обычных или легко доступных запасов нефти, увеличение затрат на добычу нетрадиционных ресурсов и снижение их прибыли от операционной деятельности. Появляется ряд ключевых тенденций в деятельности ННК на международном уровне:

- По мере расширения доступа к капиталу и развития собственной экспертизы произошел переход от первичных производителей к полностью интегрированным энергетическим компаниям.

- Высокие цены на нефть, улучшенные методы управления ННК и доступ к рынкам капитала означают, что у ННК теперь есть фи- нансовые ресурсы для участия в крупных международных сделках и их завершения.

- ННК могут лучше смягчать политические риски за рубежом посредством межправительственных отношений и переговорных стратегий.

- ННК могут терпеть международный политический риск, потому что внутренние операции, вероятно, не будут затронуты.

- Консорциум, возглавляемый исключительно ННК, является новой тенденцией, которая окажет значительное влияние на мировой нефтегазовый сектор.

Несмотря на эти преимущества для бизнеса и рынка, ННК не обязательно дисциплинируются рынком и, следовательно, относительно МНК имеют тенденцию принимать экономически неэффективные решения.

В этом исследование будут рассмотрены и обсуждены бизнес-модели ННК, проблемы и возможности, их стратегии и новые тенденции.

\section{Бизнес-модели ННК}

Бизнес-модели обычно используются для определения экономической логики согласования внутренних решений с учетом внешних условий. Как правило, они используются руководителями корпораций в качестве пояснительного, но не прогнозирующего инструмента для принятия обоснованных решений и эффективного управления. Как отмечалось ранее, большая часть мировых запасов нефти полностью принадлежит национальным организациям или частично принадлежит правительствам, которые координируют разведку и разработку нефти, добычу углеводородных ресурсов в их странах, а в некоторых случаях за пределами их границ. ННК отличаются во многих отношениях; существуют ННК импортеров и экспортеров нефти. Они различаются по своей эволюции, отношению к своим правительствам, подотчетности, эффективности, международному присутствию, степени интеграции, размеру и т. Д. Расширение сферы деятельности предполагает, что некоторые ННК будут переименованы в Международные национальные нефтяные компании (МНHК), потому что они могут работать по всему миру. МННК также выполняют функции, аналогичные ННК, с точки зрения структурных, финансовых и операционных аспектов. В последние годы МННК начали сокращать разрыв и догонять ННК. Это сближение меняет ландшафт мировой нефтегазовой отрасли благодаря сотрудничеству и конкуренции. 
НК имеет четыре ключевых элемента для успеха в нефтегазовом секторе: доступ к капиталу, доступ к технологиям, широта возможностей и партнерских отношений, а также эффективное участие на национальном уровне. В последние годы ННК по сравнению с НК добились большего прогресса в инновационных технологиях. Общим показателем инноваций являются расходы компании на (R\&D).

Saudi Aramco, Petrobras, Petronas и китайские ННК обладают собственными научно-исследовательскими возможностями. PetroChina занимает лидирующие по исследованиям и разработкам в 2012 году среди всех нефтегазовых компаний. исторически ННК имеет конкурентное преимущество перед МНК, но разрыв в настоящее время сокращается и в некоторых отношениях устраняется.

Возникающая тенденция, связанная с ростом количества ННК, изменила баланс контроля над большинством мировых углеводородных ресурсов. В 1970-х годах ННК (супер-мажоры) контролировали менее 10\% мировых запасов углеводородов, а сегодня (они контролируют более 90\%. Этот сдвиг позволил ННК расширить доступ к капиталу, человеческим ресурсам и техническим услугам напрямую, а также свои возможности для создания внутренних компетенций. ННК увеличили прямой аутсорсинг многих операций через свои нефтесервисные компании (ОФСК), вместо того чтобы обращаться к партнерам МНК. В результате МНК и независимые лица сталкиваются с новыми проблемами, чтобы оставаться актуальными для ННК, даже в самых технологически сложных проектах. Основываясь на растущем богатстве и опыте НHК, MHK все больше ориентируются на более крупные и более сложные проекты, такие как арктическое бурение и добыча на нетрадиционных месторождениях нефти и газа. Крупные независимые компании обычно следуют тому же стратегическому пути, но с небольшими проектами

\section{Сравнение НHК и МHK}

\section{HHK}

1) ННК - Доступ к капиталу:

Государственная поддержка, Расширенный доступ к акциям и заёмному капиталу на международном финансовом рынке

2) Технологии - Быстрый рост технологий и инноваций в сфере R\&D. Увеличение бюджета на R\&D

3) Широта возможностей и партнерских отношений - Фокус на внутренние операции (для ННК с внутренними ресурсами). Расширение бизнеса по всему миру. Партнерские отношения с MEK, независимыми организациями и OFSC

4) Эффективное местное участие - Работа в основном на внутреннем рынке и глобальный доступ к ресурсам. Привлечение международной рабочей силы.

MHK

1) Доступ к капиталу - Публично размещенные компании с доступом к ликвидным фондовым рынкам, банкам и покупателям облигаций.

2) Технологии - Склонность к низким расходам на $\mathrm{R} \& \mathrm{D}$, которые снижают затраты в сложных средах разработки.

3) Широта возможностей и партнерских отношений - Международный фокус. Партнерские отношения с правительствами, ННКами, ОФСК и другими МНК.

4) Эффективное местное участие- Разработка моделей для местного участия по необходимости. Более разнообразная международная рабочая сила.

Выше показаны типы контрактов ННК и их партнеров или поставщиков услуг в отношении сложности и размера проекта. Мегапроекты характеризуются высокой сложностью и очень большими размерами. ННК сотрудничают с ММК для выполнения этих контрактов о разделе продукции (PSC). Эти мегапроекты также могут быть реализованы с использованием разнесенной платы за обслуживание. Примерами такого типа могут служить соглашение Saudi Aramco с Chevron о разработке месторождений тяжелой нефти, совместное предприятие Total c Saudi Aramco по строительству нефтеперерабатывающего завода Al-Jubail для переработки тяжелой нефти и соглашение Роснефти с ExxonMobil в Арктике.

\section{Эффективность ННК}

Эффективность может быть определена как производство сырой нефти и продуктов с наименьшими возможными затратами (включая рабочую силу и материалы) относительно доступности ресурса и экологической безопасности. Следует отметить общие выводы об эффективности ННК в этом отношении. ННК, ОПЕК кажутся более эффективными по сравнению с частными компаниями из-за качества их ресурсов. ННК стран, не входящих в ОПЕК, менее эф- 
фективны с точки зрения эффективности труда и капитала. Саудовская Aramco считается эффективным ННК не из-за своих ресурсов, а потому, что у нее было долгое время для разработки модели лидерства, создания способных и умных сотрудников и создания прочных деловых отношений, по сравнению, скажем, с PDVSA или Pemex. Автор также обсудил фундаментальные различия в целях, политике и данных ННК и МНК, которые часто затрудняют любые значимые сравнения. Несмотря на эту важную квалификацию, в некоторых исследованиях была предпринята попытка составить общее представление о том, что такое ННК. Часто бывает сложно провести различие между государственной политикой и государственной собственностью организации и инфраструктуры, производящей нефть. Например, правительства могут вводить контроль цен независимо от того, является ли ресурс частным или государственным. Таким образом, некоторые недостатки, которые могут быть приписаны ННК, могут быть связаны с политикой правительства, а не с государственной собственностью ННК. Многие из ННК, признаны неэффективными, базируются в менее развитых странах и находятся под давлением, чтобы максимизировать поток средств в национальные казначейства или обеспечить энергетическую безопасность страны. Кроме того, некоторые ННК могут рассматриваться как неэффективные из-за чрезмерного укомплектования штатов, внутренних продаж и других форм плохой деловой практики. Похоже, что многие ННК производят меньше нефти на единицу рабочей силы чем частные корпорации, принадлежащие частным инвесторам. Эти организации могут ограничить текущее производство по нескольким возможным причинам:

1) Они удерживают больше продукции, потому что используют более высокие ставки дисконтирования, чем конкурирующие фирмы.

2) Они не только максимизируют экономическую прибыль, но и преследуют другие политические и социальные цели.

3) Они работают менее эффективно, что приводит к более высоким затратам на производство дорогой нефти.

В отличие от частных компаний, публичные компании часто не раскрывают достаточную информацию о своей деятельности, которая позволила бы лучше понять их деятельность. Ограниченны этим отсутствием соответствующих данных, сравнили способность государственных и частных компаний генерировать доходы от углеводородов с работниками, запасами нефти и газа в качестве входных данных. Они использовали как статистический, так и линейный подходы к программированию для определения относительной эффективности каждой организации. пришли к выводу, что, как правило, ННК технически неэффективны, поскольку используют больше сотрудников и резервируют на доллар выручки, получаемой организацией. В ситуациях, когда Государственная политика может потребовать от ННК продавать больше поставок на субсидируемые внутренние рынки, поэтому неясно, что эти более низкие доходы свидетельствуют о неэффективности самих ННК. В отличие от МНК, НHК не обязательно дисциплинируются рынком и поэтому имеют тенденцию принимать экономически неэффективные решения или мириться с непроизводительным трудом. У ННК действительно есть много преимуществ по сравнению с частными корпорациями, особенно с политической «силой» своего родительского правительства. Кроме того, они обычно, имеют больший доступ к капиталу и возможность брать на себя большие риски, не опасаясь «ставить компанию». Чтобы ННК действительно добились успеха, они должны функционировать с дисциплиной на подобее хорошо управляемой частной фирмы и, где возможно это, разделить их национальные обязанности, чтобы избежать потенциальной неэффективности, отмеченной выше. Если они преследуют более крупные социальные цели, их следует уточнить и измерить, чтобы избежать мошенничества и злоупотреблений, в то время как социальные цели выполняются экономически эффективным образом.

\section{Проблемы и возможности}

Существует несколько ключевых проблем и возможностей, которые могут быть определены HНК для обеспечения конкурентного преимущества. Эти проблемы включают в себя:

- управление рисками, отчетность;

- систему развития и удержания талантов;

- органы партнерства с МНК;

- функции финансового менеджмента в многонациональной среде;

- функции гражданства и социальной ответственности:

- специалистов;

- изменение климата и окружающей среды. 


\section{Управление рисками, отчетность}

В условиях суматохи и крупных событий, связанных с рисками, которые произошли в последние несколько лет, текущая обстановка для ведения бизнеса требует от ННК выходить за рамки своих традиционных функций по разведке, добыче и переработке сырой нефти. Для МНHК в странах-импортерах нефти и газа, таких как Китай, новая задача требует разработки глобальной инвестиционной стратегии, предназначенной для обеспечения безопасности источников углеводородов на глобальном уровне. Для НHK в значительных странах-экспортерах нефти и газа среднесрочная и долгосрочная безопасность спроса является главным приоритетом в их повестке дня. НHК как в странах-импортерах, так и в странах-экспортерах в последнее время участвуют в переговорах со своими соответствующими правительствами по решению многих вопросов, в том числе: Степени безопасности предложения и спроса на сырьевые товары. Проблемы глобализации и международное сотрудничество. Физическая безопасность активов и инфраструктуры в цепочка поставок. Работа в удаленных или враждебных энергетических сферах. Эта новая рыночная среда позволила ННК больше рисковать, чем в прошлом, стратегическими, политическими и юридическими рисками. Но было высказано предположение, что руководители ННК не чувствуют, что у них есть хорошее понимание бизнес-рисков в современных условиях, что ставит перед ННК новую задачу направить свой интерес на разработку более всеобъемлющей структуры управления рисками. По мере того, как все больше ННК начинают получать доступ к рынкам капитала они также должны рассмотреть вопрос о принятии международных стандартов бухгалтерского учета. Кроме того, необходимы новые системы отчетности, поскольку рынки перемещают бизнес из уже созданных центров в новые финансовые центры. Там, где Нью-Йорк, Лондон и Франкфурт хорошо известны, Дубай, Гонконг, Сингапур и Шанхай находятся на подъеме, и в скором времени к ним присоединится Эр-Рияд. Корпоративное управление стало острой проблемой для многих ННК. Окружающая среда, здоровье, безопасность, трудовые отношения и торговля являются важными проблемами для людей в странах, где действуют ННК. ННК должны учитывать эти вопросы в своих инвестиционных решениях. ННК, возможно, в большей степени, чем МНК, несут явную и социальную ответственность и должны нести ответственность за свои решения как в местных, так и в международных операциях. ННК должны проявлять осторожность в отношении того, как их действия влияют на общественные настроения. Поскольку ННК имеют доступ к большему количеству рынков капитала, корпоративное управление требует, чтобы они были более подотчетными и прозрачными для всех акционеров, а не только для своих стран или министерств.

\section{Развитие и удержание талантов}

Необходимость удержания талантов становится насущной проблемой для многих компаний, особенно в секторе добычи нефти. талант стал самым востребованным ресурсом после самой нефти, но в последние десятилетия одна только нефтяная промышленность США уволила более 1 миллиона рабочих мест в результате слияний и поглощений. С ростом числа МНHК усиливается конкуренция между МННК и МНК за ограниченный кадровый резерв. Одновременно это может стимулировать сотрудничество или партнерство между компаниями, пытающимися использовать одни и те же таланты. В 2002 году алжирский ННК сотрудничал с другими компаниями, чтобы получить доступ к их инженерному опыту, необходимому для улучшения его операций по экспорту сжиженного природного газа (СПГ) в Европу. Недавно ННК в России, Индии, Ливии и Китае подписали соглашения о сотрудничестве с несколькими МНК. Один из важных факторов успеха требует, чтобы ННК, смогла адаптировать свою внутреннюю культуру, чтобы учесть разные национальности и поколения рабочей силы. опыт в основном приходит из Запада, и ННК, как правило, находятся в невыгодном положении, учитывая, где они находятся и работают.

\section{Партнерство с МНК}

Некоторые ННК заинтересованы в расширении и глобализации своего бизнеса, поэтому партнерство с МНК - это стратегическое стремление расширить доступ к проектам, опыту управления и ключевым мировым рынкам. Кроме того, МНК могут принести новые технологии, критический опыт и международный опыт, которые могут быть не так легко доступны в некоторых ННК. В результате отношения МНК-ННК могут привести к инициированию перекрестных инвестиций и созданию институциональных знаний в ключевых областях тех- 
нических навыков. Партнерство между ННК и МНК позволяет использовать сектор добычи для содействия экономическому развитию страны. ННК традиционно предпочитают долгосрочные отношения, но их фокус смещается в сторону краткосрочных соглашений на основе проектов. Например, Saudi Aramco и Total создали SATORP для разработки нового проекта по переработке и нефтехимии в Саудовской Аравии. Кроме того, Saudi Aramсо и Dow сформировали SADARA для развития Саудовского интегрированного нефтехимического комплекса Aramco-Dow в Джубайле, Саудовская Аравия. Китайская национальная нефтяная корпорация (CNPC) заключила сделку в Казахстане с целью инвестирования в электростанции, железнодорожные линии и химические заводы. Еще одной новой тенденцией является то, что ННК в богатых углеводородами странах, таких как Саудовская Аравия, Венесуэла и Россия,, имеют больше власти над МНК. Т.е. у них появляется меньше возможностей, чем в прошлом, в странах с большими резервами. Это связано с тем, что ННК улучшили свой опыт и стали квалифицированными национальными операторами, используя специализированные услуги ОФСК с более выгодными сделками, приобретая небольшие фирмы для доступа к технологиям и навыкам, а также накапливая талант и опыт посредством глобальных партнерских отношений. ННК из крупных стран с формирующейся экономикой, обладающих скудными запасами углеводородов, таких как Китай и Индия, также считаются более жесткими участниками переговоров в своих отношениях с МНК.

\section{Стратегии и новые тенденции}

МНК будут оказывать существенное долгосрочное влияние на темпы освоения ресурсов в ближайшие годы. МНК Азии и России все больше конкурируют за стратегические ресурсы на Ближнем Востоке и в Евразии, в некоторых случаях заменяя западные нефтяные компании в важных мероприятиях по разработке ресурсов и переговорах. Такие компании, как Индийская корпорация по нефти и природному газу (ONGC), IndianOil Corporation Ltd. (MHK), китайская Sinopec, Китайская национальная нефтяная корпорация (CNPC) и малайзийская Petronas, расширили свою деятельность в Африке и Иране и в настоящее время осуществляют инвестиции по всей Средняя Азия. Российская «Лукойл» становится важным международным игроком в таких ключевых регионах, как Ближний Восток и Каспийский бассейн. Многие из этих новых ННК финансируются или имеют операции, субсидируемые правительствами своих стран, при этом стратегические и геополитические цели учитываются в инвестиционных решениях, а не являются чисто коммерческими соображениями. Стратегические инвестиционные и торговые альянсы для новых ННК также находятся на основе геополитических, а не экономических соображений. Взаимодействие между развивающимися ННК, крупными нефтедобывающими странами и западными странами-потребителями окажет большое влияние на будущую энергетическую безопасность и стабильность рынков нефти и газа, что вызовет много вопросов. Это та область исследований, которая требует дальнейшего изучения. Все чаще НHК занимаются переоценкой и изменением бизнес-стратегий, что имеет серьезные последствия для мировых рынков нефти и газа. В регионе GCC есть ряд компаний, которые имеют возможность расширяться за пределы обслуживания своего внутреннего рынка. Этому процессу частично препятствует неадекватность корпоративных структур и отсутствие информации в регионе GCC. На международном уровне этому препятствует рост экономического национализма и споры вокруг экономических суверенитетов, безопасность и владение активами, а также представление о том, что ННК не должны стремиться к приобретению международных нефтяных компаний и активов. Несомненно, политические соображения влияют и на международную инвестиционную политику ННК. Kuwait Petroleum Corporation является единственным НHK в регионе GCC, который интегрировал масштабируемые операции по переработке нефти и газа в форме фирменного знака Q8 в Европе, венесуэльского PDVSAquared CITGO в Соединенных Штатах; однако неудовлетворенная заявка китайской CNOOC на приобретение UNOCAL Соединенных Штатов в 2005 году является тому примером. Если МННК воспринимается как нечто большее, чем просто юридическое лицо, то его агрессивный рост будет поставлен под сомнение.

В регионе Совета сотрудничества стран Залива (GCC) некоторые региональные НHK продемонстрировали стратегическое позиционирование при совершении международных приобретений. В октябре 2008 года Международная нефтяная инвестиционная компания (IPIC) Абу-Даби увеличила свою долю в австрий- 
ской OMV с 17,6\% до 19,2\%.IPIC hassso также инвестировал в испанскую компанию Compania Espanola de Petroleos. Сауди Арамко имеет опыт инвестирования в нефтеперерабатывающие заводы и распределительные сети за рубежом в качестве партнера по совместному предприятию для миноритарных акционеров.

В свете этой динамики и новых тенденций НHК, игроки отрасли (МНК, независимые и ОФСК) должны пересмотреть два корпоративных стратегических вопроса: где играть и как успешно конкурировать с ННК. Стратегические варианты для МНК и независимых организаций включают в себя выбор пути, независимого от НHК, инвестирование в то, чтобы стать ННК предпочтительным партнером для сохранения прав на разделение производства, и внедрение модели обслуживания контрактного оператора. Эта модель предполагает сотрудничество МНК с интегрированными сервисными компаниями в лёгкие нефтяные месторождения как способ получить доступ к более крупным и сложным проектам HHK. OFSC будет постоянно улучшать эффективность и предоставление разделенных услуг, поскольку это представляет собой наиболее вероятный способ закупки услуг на месторождении в ближайшем будущем. Стратегические варианты, которые OFSC применяют для достижения успеха: продвижение и применение передовых технологий, предоставление недорогих предложений, конкурентоспособных по отношению к другим недорогим поставщикам услуг, и использование бизнес-модели оператора контракта. Таким образом, появляется ряд ключевых тенденций для руководства ННК. «Деятельность на международном уровне: C расширением доступа к капиталу и развитием собственной экспертизы произошел переход от первичных производителей к полностью интегрированным энергетическим компаниям. Высокие цены на нефть, улучшенные методы управления ННК и доступ к рынки капитала означают, что у ННК теперь есть финансовые ресурсы для участия в крупных международных сделках. Директора крупных мировых нефтяных компании могут опасаться инвестирования в нестабильные районы мира или там, где были введены международные санкции, ННК принимая решения должно быть несовместимы с национальной политикой и вряд ли будут затруднены требованиями корпоративного управления и действиями заинтересованных сторон. ННК лучше способны смягчать зарубежные политические риски посредством межправительственных отношений и стратегий ведения переговоров. ННК могут лучше переносить политический риск, поскольку внутренние операции вероятны быть незатронутым. Консорциум, возглавляемый исключительно ННК, является новой тенденцией, которая, скорее всего, сохранится. наблюдается рост числа ННК, которые все больше напоминают международные корпорации с полным набором ресурсов и со специальным активом несущий свидетельство своей родительской нации

В его статье был рассмотрен и обсужден вопрос об эволюции ННК, включая новые роли, возможности и возникающие проблемы, с которыми сталкивается нефтегазовая промышленность. Бизнес-модели и характеристики различных нефтегазовых компаний также обсуждались в контексте ННК. В исследовании обсуждался рост международной деятельности ННК и последствия для будущих поставок, безопасности и ценообразования на нефть. ННК продолжат агрессивно отслеживать новые возможности роста: с точки зрения резервов и доходов, связанных с растущим доступом к рынкам капитала, увеличением прибыли, расширением участия в технологиях достижения и все более эффективное управление проектами и другие технические возможности. В настоящее время ННК решают новые проблемы, требующие более комплексного подхода к риску, чем в прошлом. Успешный рост ННК зависит от их ответов на новые вызовы, которые включают более эффективное корпоративное управление и прозрачность, финансовые управление рисками, развитие и удержание талантов, а также более активные усилия по устранению внешних факторов, включая изменение климата. ННК изменяют игровое поле путем глобализации своих бизнес-портфелей и пересечения национальных границ, осуществления Вертикальная интеграция в цепочке поставок и привлечение капитала с глобальных рынков. Стратегические партнерства между НHК и супермажорами дают ННК львиную долю выгод, поскольку ННК диверсифицируют свои иностранные активы, участвуют в разработке нетрадиционных резервов, новейших технологиях, а также приобретают навыки и опыт. Подводя итог, следует отметить, что количество ННК растет, поскольку они имеют ряд преимуществ по сравнению с МНК. В то же время, эти ННК могут 
добиться большего успеха, если они смогут изу- использования их наиболее полезных навыков, чить различные практики, которые усовершен- поиска путей снижения рисков., и приобретение ствовали МНК, а именно в работе с различными международными финансовыми и налоговыми органами, сотрудничая друг с другом в целях и удержание лучшего интеллектуального капитала наиболее экономическим эффективными способами

\section{Библиографический список}

1. https://hbswk.hbs.edu/item/oil-price-fallout-what-happens-next

2. https://www.rbc.ru/business/08/11/2018/5be488b69a7947826089105f

3. https:/www.bain.com/insights/industry-insights/oil-and-gas-insights/

4. https://www.bloomberg.com/opinion/articles/2019-02-14/saudi-aramco-expands-while-oil-retreats

5. https://www.oilandgasiq.com/integrity-hse-maintenance/whitepapers/the-keys-to-asset-management-in-theoil-and-gas-in

6. https://www.ektinteractive.com/business-processes-risk-management/

7. https://medium.com/business-process-management-software-comparisons/7-key-operational-excellencechallenges-facing-the-oil-and-gas-industry-775fec5009f5

8. https://www.bain.com/insights/large-project-management-in-oil-and-gas/

9. https://www2.deloitte.com/rs/en/pages/energy-and-resources/articles/oil-and-gas-talent-management.html

Поступила в редакциюю 15.02.2019 